\title{
Outcomes for Lymph Node-Positive Cutaneous Melanoma Over Two Decades
}

\author{
Steve R. Martinez • Warren H. Tseng • \\ Shawn E. Young
}

Published online: 14 December 2010

(C) The Author(s) 2010. This article is published with open access at Springerlink.com

\begin{abstract}
Background Our aim was to demonstrate that, despite advances in treatment and surveillance of node-positive cutaneous melanoma, rates of overall survival (OS) and melanoma-specific survival (MSS) have not changed over the last two decades.

Methods We used the Surveillance, Epidemiology, and End Results (SEER) database of the National Cancer Institute to identify patients with node-positive cutaneous melanoma. Patients were categorized by treatment era; the first era encompassed patients diagnosed from 1988 to 1999 and the second era 2000 to 2006. Multivariate Cox proportional hazards models compared rates of OS and MSS between treatment eras while controlling for known prognostic factors. We reported risks of death as hazard ratios (HR) with 95\% confidence intervals (CI) and set significance at $P \leq 0.05$.

Results Entrance criteria were met by 6,868 patients, $1,631(23.8 \%)$ treated in era I and 5,237 (76.3\%) treated in era II. On multivariate analysis, era II patients did not demonstrate a significantly different risk of death from any cause (HR 0.89, CI $0.79-1.01 ; P<0.08$ ), but they did have a lower risk of melanoma-specific mortality (HR 0.81, CI $0.71-0.93 ; P=0.003$ ) relative to their era I counterparts.
\end{abstract}

S. R. Martinez ( $\square)$. W. H. Tseng

Department of Surgery, Division of Surgical Oncology

Sacramento, University of California at Davis,

4501 X Street, Suite 3010, Sacramento, CA 95817, USA

e-mail: steve.martinez@ucdmc.ucdavis.edu

S. E. Young

Division of Surgical Oncology, Exempla/St. Joseph Comprehensive Cancer Center, 1835 Franklin Street, Denver, CO80218, USA
Conclusions Over nearly two decades, MSS but not OS has improved for AJCC stage III melanoma patients. Stage migration is likely responsible for any improvement in MSS among patients in the most recently diagnosed era.

\section{Introduction}

Lymph node status remains the dominant prognostic factor for cutaneous melanoma. Current American Joint Committee on Cancer (AJCC)/International Union against Cancer (UICC) staging reflects the heterogeneous nature of lymph node positive melanoma. Patients are categorized according to the number and volume of lymph nodes involved as stage IIIA, IIIB, or IIIC. While the average 5-year overall survival (OS) rate for stage III melanoma patients is approximately $45 \%$, the survival rates for IIIA, IIIB, and IIIC disease are 67, 53, and 26\%, respectively [1]. These survival rates are quite dramatic in comparison to those experienced by patients without lymph node metastases. Patients with localized AJCC stage I and II melanoma have 10-year survival rates approximating 85 and $55 \%$, respectively [1].

The chasm between survival rates in patients with localized and regionally metastatic disease has, over the last two decades, motivated the development of new approaches for the management of patients with lymph node metastases. Advances in the fields of medical oncology, surgery, radiology, and radiation oncology have been well documented, many with influence on OS and melanoma-specific survival (MSS). Nonspecific immunotherapy has demonstrated significant improvement in recurrence-free survival with the administration of high-dose interferon $\alpha$-2b (IFN $\alpha-2 b)$ in stage III melanoma patients [2-6]. Although OS was not the primary study endpoint, OS benefits were seen 
with IFN $\alpha-2 b[2-6]$. Surgical management of stage III melanoma has included the use of therapeutic lymph node dissection, elective lymph node dissection, and, most recently, lymphatic mapping/sentinel lymph node biopsy (LM/SNB) with or without completion lymph node dissection, as indicated by the pathologic status of the sentinel node [7-9]. Improved patient outcomes resulting from advances in disease staging attributed to imaging technology such as computed tomography (CT), magnetic resonance imaging (MRI), and positron emission tomography (PET) are admittedly limited. Studies investigating the contribution of CT and MRI indicate that approximately $7 \%$ of asymptomatic patients are diagnosed with unsuspected disease that went undetected in previous imaging studies [10-12]. At the time of diagnosis, the majority of patients with AJCC stage III melanoma will not demonstrate evidence of advanced disease on imaging studies [13, 14]. Finally, the development of conformal techniques of radiation delivery has decreased the morbidity of external beam radiotherapy, and in select clinical situations, application of radiation therapy in addition to surgery decreases local recurrence rates and may improve MSS [15-20]. Despite these advances, lymph node metastases continue to portend a poor prognosis.

We hypothesized that advances in melanoma treatment during the last 20 years have been insufficient to influence rates of OS and MSS. To test this hypothesis, we used a national, population-based database.

\section{Patients and methods}

The Surveillance, Epidemiology, and End Results (SEER) database of the National Cancer Institute was used to identify all patients with lymph node positive (AJCC stage III) cutaneous melanoma diagnosed from 1988 to 2006. SEER collects cancer incidence and survival data from 17 population-based cancer registries representing $26 \%$ of the U.S. population. Current SEER registries consist of: the states of Connecticut, Hawaii, Iowa, Kentucky, Louisiana, New Jersey, New Mexico, and Utah; the metropolitan areas of Atlanta, Detroit, San Francisco-Oakland, Seattle-Puget Sound, and San Jose-Monterey; and the Alaska Native Tumor Registry, rural Georgia, Greater California, and Los Angeles County. SEER registries routinely collect data on patient demographics, primary tumor site, tumor morphology, stage at diagnosis, and first course of treatment.

All cases of primary, histologically confirmed, cutaneous melanoma with lymph node metastasis were eligible for the study. We restricted eligibility to patients diagnosed between 1988 and 2006. Patients with distant metastases at the time of diagnosis were excluded. Finally, we excluded cases identified by death certificate or autopsy and cases with missing cause of death. The final sample included 6,868 patients.

Patients were divided into two treatment eras: 1988-1999 (era I) and 2000-2006 (era II). Comparisons of patients treated during the two eras were performed with the chi-square test. We compared univariate rates of OS and MSS according to treatment era with the Kaplan-Meier method. Additional survival comparisons were made for the following patient, tumor, and treatment-specific factors: age at diagnosis (using the median split method for age $\leq 55$ vs $>55$ years), sex, Breslow depth $(0, \leq 1,1.01-2,2.01-4$, $>4 \mathrm{~mm}$, unknown), number of metastatic lymph nodes $(1,2-3, \geq 4)$, presence of ulceration (non-ulcerated, ulcerated), and type of primary surgery (amputation, tumor ablation, local excision, wide excision with $1-2 \mathrm{~cm}$ margins, wide excision with $>2 \mathrm{~cm}$ margins, none, unknown). Differences between or among survival curves were assessed via the log-rank test. Date and cause of death were available via database linkage to death certificate data. Survival time was calculated as the number of completed months between the date of diagnosis and whichever occurred first: date of death, date last known to be alive, or December 31, 2006. The endpoints for the present study were OS and MSS. Patients who were lost to follow-up or survived beyond December 31, 2006, were coded as censored observations.

The proportional hazards model was confirmed graphically using the "stphtest" from STATA, version 10 (StataCorp, College Station, TX). We used Cox proportional hazards models to assess the effect of treatment era on OS and MSS, while adjusting for factors found to be significant on univariate analysis. Risks of overall and melanomaspecific mortality were reported as $\mathrm{HR}$ with $95 \% \mathrm{CI}$; significance was set at $P \leq 0.05$. All statistical analyses were two-tailed and were performed with STATA, version 10.

\section{Results}

A cohort of 6,868 patients with lymph node metastasis positive (AJCC stage III) cutaneous melanoma met study entry criteria. Of these, 1,631 (23.8\%) were treated during era I (1988-1999) and 5,237 (76.3\%) were treated during era II (2000-2006). Characteristics of the study population, based on treatment era, are presented in Table 1. Briefly, significant differences were noted between patients treated during era I and era II with respect to patient age, primary tumor Breslow depth, ulceration, number of lymph node metastases, and type of primary surgery (all $P<0.001$ ). Of note, data regarding Breslow depth were unknown for $20.5 \%$ of era I patients and $10.9 \%$ of era II patients. Type of primary surgery was unknown for $68.9 \%$ of era I patients and $29 \%$ of era II patients. The number of lymph node metastases was unknown for 8.2 and $2.4 \%$ of era I and era II patients, respectively. 
Table 1 Patient, tumor, and treatment-specific factors according to treatment era

\begin{tabular}{|c|c|c|c|}
\hline Variable & $\begin{array}{l}\text { Era I: } 1988-1999 \\
(n=1,631)\end{array}$ & $\begin{array}{l}\text { Era II: } 2000-2006 \\
(n=5,237)\end{array}$ & $P$ value \\
\hline \multicolumn{4}{|l|}{ Age, years } \\
\hline$\leq 56$ & 910 & 2,592 & \multirow[t]{2}{*}{$<0.001$} \\
\hline$>56$ & 721 & 2,645 & \\
\hline \multicolumn{4}{|l|}{ Sex } \\
\hline Male & 1,045 & 3,324 & \multirow[t]{2}{*}{$=0.66$} \\
\hline Female & 586 & 1,913 & \\
\hline \multicolumn{4}{|c|}{ Breslow depth, mm } \\
\hline 0 & 38 & 109 & \multirow[t]{6}{*}{$<0.001$} \\
\hline$\leq 1$ & 233 & 897 & \\
\hline $1.01-2$ & 299 & 1,261 & \\
\hline $2.01-4$ & 411 & 1,327 & \\
\hline$>4$ & 315 & 1,072 & \\
\hline Unknown & 335 & 571 & \\
\hline \multicolumn{4}{|l|}{ Ulceration } \\
\hline Absent & 1,378 & 3,682 & \multirow[t]{2}{*}{$<0.001$} \\
\hline Present & 253 & 1555 & \\
\hline \multicolumn{4}{|c|}{ Number of lymph node metastases } \\
\hline 1 & 886 & 3,225 & \multirow[t]{4}{*}{$<0.001$} \\
\hline $2-3$ & 377 & 1,355 & \\
\hline$\geq 4$ & 234 & 532 & \\
\hline Unknown & 134 & 125 & \\
\hline \multicolumn{4}{|l|}{ Surgery } \\
\hline Amputation & 2 & 89 & \multirow[t]{7}{*}{$<0.001$} \\
\hline Ablation & 1 & 2 & \\
\hline Local excision & 50 & 1054 & \\
\hline $\begin{array}{l}\text { Wide excision } \\
\qquad(1-2 \mathrm{~cm})\end{array}$ & 427 & 3,555 & \\
\hline $\begin{array}{l}\text { Wide excision } \\
\qquad(>2 \mathrm{~cm})\end{array}$ & 0 & 264 & \\
\hline None & 27 & 246 & \\
\hline Unknown & 1,124 & 29 & \\
\hline
\end{tabular}

Median OS and MSS were 65 and 124 months, respectively, for the study population as a whole. Rates of 5-year OS and MSS were 51 and 59\%, respectively. Median OS was 47 months for patients treated during era I and 70 months for those treated during era II. Median MSS was 64 months for patients treated during era I and not yet achieved for those treated during era II. Rates of 5-year OS were 45 and $54 \%$ for era I and II patients, respectively. Five-year MSS rates were $51 \%$ for era I patients and $62 \%$ for era II patients.

Univariate analysis of OS and MSS demonstrated all factors as significant predictors of OS and MSS (age, sex, Breslow depth, tumor ulceration, number of lymph node metastases, and type of surgery; all $P<0.001$. Specifically, treatment era was a significant predictor of both OS (Fig. 1) and MSS (Fig. 2) on univariate analysis.

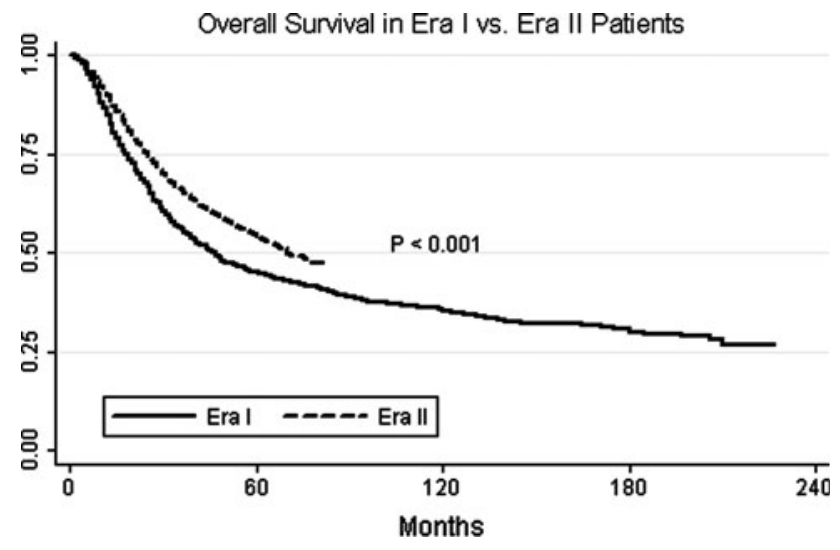

Fig. 1 Kaplan-Meier curves of overall survival comparing patients treated during era I (1988-1999) with those treated in era II (2000-2006)

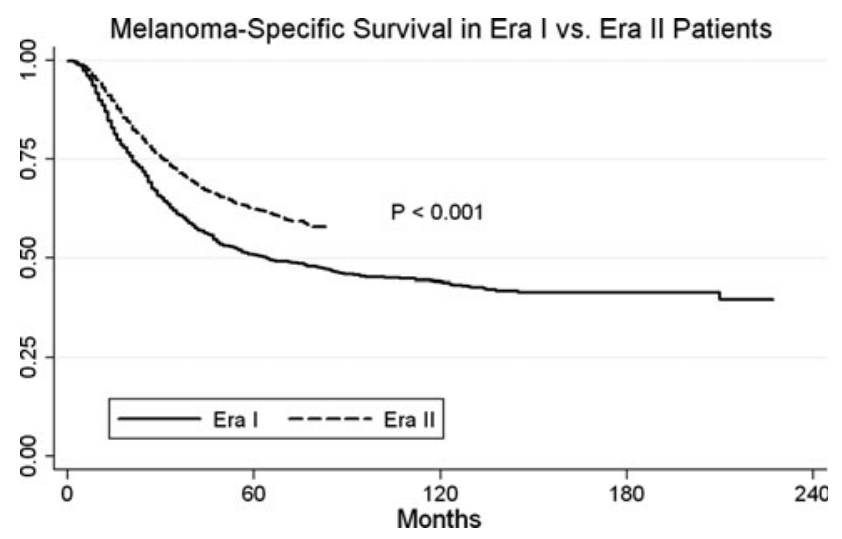

Fig. 2 Kaplan-Meier curves of melanoma-specific survival comparing patients treated during era I (1988-1999) and era II (2000-2006)

Multivariate models were created for both OS and MSS (Table 2). Increasing age (HR 1.03, CI 1.02-1.03; $P<0.001$ ), Breslow depth of 2.01-4 mm (HR 1.52, CI $1.33-1.72 ; P<0.001$ ), Breslow depth unknown (HR 1.19, CI $1.03-1.37 ; P=0.017$ ), primary tumor ulceration (HR 1.29 , CI $1.18-1.41 ; P<0.001)$, and increasing number of nodal metastases (2-3 metastases: HR 1.46, CI 1.33-1.59; $P<0.001 ; \geq 4$ metastases: HR 2.54, CI 2.28-2.83, $P<0.001$; unknown number of metastases: HR 2.10, CI $1.79-2.47 ; P<0.001)$ were predictive of an increased risk of death from any cause. Female sex (HR 0.79, CI 0.73-0.86; $P<0.001$ ) and Breslow depth $\leq 1 \mathrm{~mm}$ (HR 0.84 , CI $0.73-0.96 ; P=0.01$ ) both predicted a decreased risk of death from any cause. Of note, in contrast to univariate analysis findings, patients treated during era II did not differ in risk of death relative to their era I counterparts (HR 0.89, CI 0.78-1.01; $P=0.065$ ).

Increasing age similarly predicted an increased risk of melanoma-specific mortality (HR 1.02, CI 1.02-1.02; $P<0.001)$. Additional factors predicting a decreased risk 
Table 2 Multivariate Cox proportional hazards models of overall survival and melanoma-specific survival

\begin{tabular}{|c|c|c|c|}
\hline & $\begin{array}{l}\text { Hazard } \\
\text { ratio }\end{array}$ & $\begin{array}{l}95 \% \text { confidence } \\
\text { interval }\end{array}$ & $P$ value \\
\hline \multicolumn{4}{|l|}{ Overall survival } \\
\hline Age & 1.03 & $1.02-1.03$ & $<0.001 *$ \\
\hline \multicolumn{4}{|l|}{ Sex } \\
\hline Male (referent) & (referent) & (referent) & (referent) \\
\hline Female & 0.79 & $0.73-0.86$ & $<0.001^{*}$ \\
\hline \multicolumn{4}{|l|}{ Breslow depth, mm } \\
\hline $0 \mathrm{~mm}$ (referent) & (referent) & (referent) & (referent) \\
\hline$\leq 1 \mathrm{~mm}$ & 0.84 & $0.73-0.96$ & $=0.01 *$ \\
\hline $1.01-2 \mathrm{~mm}$ & 1.10 & $0.97-1.25$ & $=0.148$ \\
\hline $2.01-4 \mathrm{~mm}$ & 1.52 & $1.33-1.72$ & $<0.001^{*}$ \\
\hline$>4 \mathrm{~mm}$ & 0.88 & $0.63-1.24$ & $=0.457$ \\
\hline Unknown & 1.19 & $1.03-1.37$ & $=0.017 *$ \\
\hline \multicolumn{4}{|l|}{ Ulceration } \\
\hline Absent (referent) & (referent) & (referent) & (referent) \\
\hline Present & 1.29 & $1.18-1.41$ & $<0.001 *$ \\
\hline \multicolumn{4}{|c|}{ Number of lymph Node metastases } \\
\hline 1 (referent) & (referent) & (referent) & (referent) \\
\hline $2-3$ & 1.46 & $1.33-1.59$ & $<0.001^{*}$ \\
\hline$\geq 4$ & 2.54 & $2.28-2.83$ & $<0.001^{*}$ \\
\hline Unknown & 2.10 & $1.79-2.47$ & $<0.001^{*}$ \\
\hline \multicolumn{4}{|l|}{ Type of surgery } \\
\hline $\begin{array}{l}\text { Local excision } \\
\text { (referent) }\end{array}$ & (referent) & (referent) & (referent) \\
\hline Amputation & 2.58 & $0.64-10.39$ & $=0.182$ \\
\hline Ablation & 1.11 & $0.81-1.52$ & $=0.531$ \\
\hline $\begin{array}{l}\text { Wide excision } \\
\quad(1-2 \mathrm{~cm})\end{array}$ & 1.07 & $0.83-1.38$ & $=0.60$ \\
\hline $\begin{array}{l}\text { Wide excision } \\
(>2 \mathrm{~cm})\end{array}$ & 1.09 & $0.92-1.30$ & $=0.317$ \\
\hline None & 0.90 & $0.79-1.02$ & $=0.094$ \\
\hline Unknown & 0.78 & $0.59-1.04$ & $=0.096$ \\
\hline \multicolumn{4}{|l|}{ Era } \\
\hline Era I (referent) & (referent) & (referent) & (referent) \\
\hline Era II & 0.89 & $0.78-1.01$ & $=0.065$ \\
\hline \multicolumn{4}{|c|}{ Melanoma-specific survival } \\
\hline Age & 1.02 & $1.02-1.02$ & $<0.001 *$ \\
\hline \multicolumn{4}{|l|}{ Sex } \\
\hline Male (referent) & (referent) & (referent) & (referent) \\
\hline Female & 0.80 & $0.73-0.88$ & $<0.001 *$ \\
\hline \multicolumn{4}{|l|}{ Breslow depth, mm } \\
\hline $0 \mathrm{~mm}$ (referent) & (referent) & (referent) & (referent) \\
\hline$\leq 1 \mathrm{~mm}$ & 0.83 & $0.71-0.97$ & $=0.023^{*}$ \\
\hline $1.01-2 \mathrm{~mm}$ & 1.16 & $1.01-1.34$ & $=0.038^{*}$ \\
\hline $2.01-4 \mathrm{~mm}$ & 1.61 & $1.39-1.87$ & $<0.001^{*}$ \\
\hline$>4 \mathrm{~mm}$ & 0.91 & $0.62-1.33$ & $=0.646$ \\
\hline Unknown & 1.29 & $1.10-1.51$ & $=0.002 *$ \\
\hline
\end{tabular}

Table 2 continued

\begin{tabular}{|c|c|c|c|}
\hline & $\begin{array}{l}\text { Hazard } \\
\text { ratio }\end{array}$ & $\begin{array}{l}95 \% \text { confidence } \\
\text { interval }\end{array}$ & $P$ value \\
\hline \multicolumn{4}{|l|}{ Ulceration } \\
\hline Absent (referent) & (referent) & (referent) & (referent) \\
\hline Present & 1.32 & $1.19-1.47$ & $<0.001^{*}$ \\
\hline \multicolumn{4}{|c|}{ Number of lymph node metastases } \\
\hline 1 (referent) & (referent) & (referent) & (referent) \\
\hline $2-3$ & 1.51 & $1.36-1.67$ & $<0.001^{*}$ \\
\hline$\geq 4$ & 2.71 & $2.41-3.06$ & $<0.001^{*}$ \\
\hline Unknown & 2.20 & $1.84-2.64$ & $<0.001^{*}$ \\
\hline \multicolumn{4}{|l|}{ Type of surgery } \\
\hline $\begin{array}{l}\text { Local excision } \\
\text { (referent) }\end{array}$ & (referent) & (referent) & (referent) \\
\hline Amputation & NA & NA & NA \\
\hline Ablation & 1.18 & $0.84-1.68$ & $=0.34$ \\
\hline $\begin{array}{l}\text { Wide excision } \\
\quad(1-2 \mathrm{~cm})\end{array}$ & 1.06 & $0.80-1.41$ & $=0.67$ \\
\hline $\begin{array}{l}\text { Wide excision } \\
\quad(>2 \mathrm{~cm})\end{array}$ & 1.04 & $0.86-1.26$ & $=0.713$ \\
\hline None & 0.86 & $0.75-0.99$ & $=0.035^{*}$ \\
\hline Unknown & 0.68 & $0.49-0.96$ & $=0.028 *$ \\
\hline \multicolumn{4}{|l|}{ Era } \\
\hline Era I (referent) & (referent) & (referent) & (referent) \\
\hline Era II & 0.81 & $0.70-0.93$ & $=0.003 *$ \\
\hline
\end{tabular}

of melanoma-specific mortality included Breslow depth of 1.01-2 mm (HR 1.16, CI 1.01-1.34; $P=0.038$ ), Breslow depth of 2.01-4 mm (HR 1.61, CI 1.39-1.87; $P<0.001$ ), Breslow depth unknown (HR 1.29, CI 1.10-1.51; $P=0.002$ ), primary tumor ulceration (HR 1.32, CI $1.19-1.47 ; P<0.001)$, and increasing number of nodal metastases (2-3 metastases: HR 1.51, CI 1.36-1.67; $P<0.001 ; \geq 4$ metastases: HR 2.71, CI 2.41-3.06; $P<0.001$; unknown number of metastases: HR 2.20, CI $1.84-2.64 ; P<0.001)$. A decreased risk of death from melanoma was noted for female sex (HR 0.80, CI 0.73-0.88; $P<0.001$ ), Breslow depth $\leq 1 \mathrm{~mm}$ (HR 0.83, CI $0.71-0.97 ; P=0.023$ ), no primary surgery (HR 0.86 , CI $0.75-0.99 ; P=0.035)$, unknown type of primary surgery (HR 0.68 , CI $0.49-0.96 ; P=0.028$ ), and treatment during era II (HR 0.81, CI 0.70-0.93; $P=0.003$ ). Patients treated during era II experienced a $19 \%$ decreased risk of death due to melanoma relative to their era I counterparts.

\section{Discussion}

We hypothesized that the advances in AJCC stage III melanoma treatment have not led to improvements in OS 
and MSS. We used the SEER database and categorized patients into remote (era I, 1988-1999) and current (era II, 2000-2006) eras. Our findings indicate that MSS, but not OS, was improved for patients treated during era II.

There are several potential explanations for this finding. The MSS benefit demonstrated by patients in era II may be due to stage migration. Because the first randomized controlled data demonstrating the accuracy of LM/SNB were not published until 1999 [21], era II patients were more likely than era I patients to have undergone a LM/SNB procedure for regional lymph node staging. LM/SNB is well established as the standard means of evaluating the regional nodal basin of localized melanoma [22, 23]. Because the sentinel node represents the most likely site of tumor metastasis in the regional lymphatic basin, focused pathologic examination of the sentinel node has become a useful method of ultrastaging the regional nodes [21, 24, 25]. Microscopic tumor burden was not routinely detectable prior to identification and detailed analysis of the sentinel node. Patients from era I with microscopic regional disease in their lymph node dissection specimen would not have easily been detected by an unfocused pathology exam in which nodes were traditionally only bivalved. As a result, a proportion of patients in the era I prior to development of LM/SNB would likely have been diagnosed as stage II [26], whereas those in era II would be diagnosed as stage III. Because LM/SNB was not routinely available during the majority of era I, nodal metastases would likely have been diagnosed at a more advanced stage in patients from this era. Balch et al. demonstrated that nodal tumor burden matters; 5-year survival for stage III melanoma patients with lymph node micrometastases was $67 \%$, but it was $43 \%$ for those with macrometastases in a population of 2,313 patients diagnosed and treated in the contemporary era [27]. In this regard, our findings are consistent with those of the first Multicenter Sentinel Lymphadenectomy Trial (MSLT-I), which randomized patients with intermediate-thickness melanomas to wide excision alone or wide excision plus LM/SNB and completion lymphadenectomy in cases of sentinel node metastasis [25]. This trial concluded that there was no MSS benefit to LM/SNB. However, when comparing the population at risk, namely those patients who ultimately developed nodal metastases in the wide excision group and those patients with sentinel node metastases in the comparison group, there was a clear benefit to LM/SNB in terms of MSS. Indeed, this is exactly what we appreciated in our study. While we do not have data regarding the indications for lymphadenectomies in era 1 and era 2 patients, we have shown that those patients more likely to receive LM/SNB (i.e., those diagnosed and treated after 1999) demonstrated a survival advantage.

Our study was subject to limitations. We excluded cases of stage III melanoma prior to 1988 , primarily because cases from these years had incomplete data regarding the number of lymph node metastases that would have made multivariate comparisons prohibitive. Furthermore, while we have good information regarding the type of treatment patients received (surgery, radiation, or both), we do not have data on the appropriateness or adequacy of that treatment for individual patients. It is unlikely, given our sample size, for such deficiencies to play a significant role in our results. Perhaps most significantly, we have no information regarding whether patients received chemotherapy, immunotherapy, biotherapy, or any other adjuvant medical treatment with the exception of radiation therapy, as SEER does not collect these data. Because IFN $\alpha-2 b$ has demonstrated recurrence free and OS benefits [2-6], and because use of IFN $\alpha-2 b$ has taken place almost entirely within era II, it is also possible that this may have influenced our results. SEER also does not provide important information regarding patients' past medical history or co-morbidities that may influence OS outcomes [28]. Furthermore, the current AJCC staging system incorporates primary tumor mitotic rate as a prognostic factor [29], but SEER does not record this at present. It is possible that differing mitotic rates between the two eras could have contributed to MSS differences. Similarly, it is not possible to make a perfect multivariate model. It is possibleindeed likely-that additional factors, some as yet unidentified, could have contributed to the MSS differences noted in our study. As indicated previously, some data fields are incomplete in the SEER database. In the spirit of full disclosure, we listed those variables for which data were unknown and included the unknowns in the multivariate analyses.

SEER data are beneficial in several respects. Populationbased data are more readily generalized than single institution studies, which are subject to referral bias. Our study represents a cross section of outcomes at university health centers, rural community hospitals, and regional cancer centers.

Over nearly two decades, melanoma-specific survival, but not overall survival, has improved for AJCC stage III melanoma patients. Stage migration is likely responsible for any improvement in MSS among patients in the most recently diagnosed era, although the increase in use of biologic agents such as interferon alpha may also play a role. New treatments for the management of stage III melanoma are needed, and patients should be encouraged to enter clinical trials.

Acknowledgments This work was supported by Grant UL1 RR024146 from the National Center for Research Resources (NCRR), a component of the National Institutes of Health $(\mathrm{NIH})$, and $\mathrm{NIH}$ Roadmap for Medical Research. The content is solely the responsibility of the authors and does not necessarily represent the official views of the NCRR or NIH. Information on NCRR is available at 
http://www.ncrr.nih.gov/. Information on Re-engineering the Clinical Research Enterprise can be obtained from http://nihroadmap.nih.gov/ clinicalresearch/overview-translational.asp.

Open Access This article is distributed under the terms of the Creative Commons Attribution Noncommercial License which permits any noncommercial use, distribution, and reproduction in any medium, provided the original author(s) and source are credited.

\section{References}

1. Balch CM, Soong SJ, Atkins MB et al (2004) An evidence-based staging system for cutaneous melanoma. CA Cancer J Clin 54:131-149

2. Bottomley A, Coens C, Suciu S et al (2009) Adjuvant therapy with pegylated interferon alfa- $2 \mathrm{~b}$ versus observation in resected stage III melanoma: a phase III randomized controlled trial of health-related quality of life and symptoms by the European Organisation for Research and Treatment of Cancer Melanoma Group. J Clin Oncol 27:2916-2923

3. Eggermont AM, Suciu S, Santinami M et al (2008) Adjuvant therapy with pegylated interferon alfa- $2 b$ versus observation alone in resected stage III melanoma: final results of EORTC 18991, a randomised phase III trial. Lancet 372(9633):117-126

4. Kirkwood JM, Ibrahim JG, Sosman JA et al (2001) High-dose interferon alfa- $2 \mathrm{~b}$ significantly prolongs relapse-free and overall survival compared with the GM2-KLH/QS-21 vaccine in patients with resected stage IIB-III melanoma: results of intergroup trial E1694/S9512/C509801. J Clin Oncol 19:2370-2380

5. Kirkwood JM, Manola J, Ibrahim J et al (2004) A pooled analysis of Eastern Cooperative Oncology Group and intergroup trials of adjuvant high-dose interferon for melanoma. Clin Cancer Res 10:1670-1677

6. Kirkwood JM, Strawderman MH, Ernstoff MS et al (1996) Interferon alfa-2b adjuvant therapy of high-risk resected cutaneous melanoma: the Eastern Cooperative Oncology Group Trial EST 1684. J Clin Oncol 14:7-17

7. Chakera AH, Hesse B, Burak Z et al (2009) EANM-EORTC general recommendations for sentinel node diagnostics in melanoma. Eur J Nucl Med Mol Imaging 36:1713-1742

8. Nowecki ZI, Rutkowski P, Michej W (2008) The survival benefit to patients with positive sentinel node melanoma after completion lymph node dissection may be limited to the subgroup with a primary lesion Breslow thickness greater than 1.0 and less than or equal to $4 \mathrm{~mm}$ (pT2-pT3). Ann Surg Oncol 15:2223-2234

9. Phan GQ, Messina JL, Sondak VK et al (2009) Sentinel lymph node biopsy for melanoma: indications and rationale. Cancer Control 16:234-239

10. Buzaid AC, Tinoco L, Ross MI et al (1995) Role of computed tomography in the staging of patients with local-regional metastases of melanoma. J Clin Oncol 13:2104-2108

11. Johnson TM, Fader DJ, Chang AE et al (1997) Computed tomography in staging of patients with melanoma metastatic to the regional nodes. Ann Surg Oncol 4:396-402

12. Silverman PM, Heaston DK, Korobkin M et al (1984) Computed tomography in the detection of abdominal metastases from malignant melanoma. Invest Radiol 19:309-312

13. Hafner J, Schmid MH, Kempf W et al (2004) Baseline staging in cutaneous malignant melanoma. Br J Dermatol 150:677-686
14. Miranda EP, Gertner M, Wall J et al (2004) Routine imaging of asymptomatic melanoma patients with metastasis to sentinel lymph nodes rarely identifies systemic disease. Arch Surg 139:831-836; discussion 836-837

15. Ang KK, Peters LJ, Weber RS et al (1994) Postoperative radiotherapy for cutaneous melanoma of the head and neck region. Int J Radiat Oncol Biol Phys 30:795-798

16. Ballo MT, Zagars GK, Gershenwald JE et al (2004) A critical assessment of adjuvant radiotherapy for inguinal lymph node metastases from melanoma. Ann Surg Oncol 11:1079-1084

17. Fuhrmann D, Lippold A, Borrosch F et al (2001) Should adjuvant radiotherapy be recommended following resection of regional lymph node metastases of malignant melanomas? $\mathrm{Br} \mathrm{J}$ Dermatol 144:66-70

18. Gyorki DE, Ainslie J, Joon ML et al (2004) Concurrent adjuvant radiotherapy and interferon-alpha2b for resected high risk stage III melanoma- $\mathbf{a}$ retrospective single centre study. Melanoma Res 14:223-230

19. Strom EA, Ross MI (1995) Adjuvant radiation therapy after axillary lymphadenectomy for metastatic melanoma: toxicity and local control. Ann Surg Oncol 2:445-449

20. Agrawal S, Kane JM 3rd, Guadagnolo BA et al (2009) The benefits of adjuvant radiation therapy after therapeutic lymphadenectomy for clinically advanced, high-risk, lymph nodemetastatic melanoma. Cancer 115:5836-5844

21. Morton DL, Thompson JF, Essner R et al (1999) Validation of the accuracy of intraoperative lymphatic mapping and sentinel lymphadenectomy for early-stage melanoma: a multicenter trial. Multicenter Selective Lymphadenectomy Trial Group. Ann Surg 230:453-463; discussion 463-465

22. Cochran AJ, Wen DR, Morton DL (1992) Management of the regional lymph nodes in patients with cutaneous malignant melanoma. World J Surg 16:214-221

23. Morton DL, Wen DR, Wong JH et al (1992) Technical details of intraoperative lymphatic mapping for early stage melanoma. Arch Surg 127:392-399

24. Morton DL, Hoon DS, Cochran AJ et al (2003) Lymphatic mapping and sentinel lymphadenectomy for early-stage melanoma: therapeutic utility and implications of nodal microanatomy and molecular staging for improving the accuracy of detection of nodal micrometastases. Ann Surg 238:538-549; discussion 549-550

25. Morton DL, Thompson JF, Cochran AJ et al (2006) Sentinel-node biopsy or nodal observation in melanoma. $\mathrm{N}$ Engl $\mathrm{J}$ Med 355: 1307-1317

26. Cochran AJ, Wen DR, Morton DL (1988) Occult tumor cells in the lymph nodes of patients with pathological stage I malignant melanoma. An immunohistological study. Am J Surg Pathol 12:612-618

27. Balch CM, Gershenwald JE, Soong SJ et al (2010) Multivariate analysis of prognostic factors among 2,313 patients with stage III melanoma: comparison of nodal micrometastases versus macrometastases. J Clin Oncol 28:2452-2459

28. Yu JB, Gross CP, Wilson LD et al (2009) NCI SEER public-use data: applications and limitations in oncology research. Oncology (Williston Park) 23:288-295

29. Balch CM, Gershenwald JE, Soong SJ et al (2009) Final version of 2009 AJCC melanoma staging and classification. J Clin Oncol 27:6199-6206 